\title{
Surface functionalization of 3D printed structures: Aesthetic and antibiofouling properties
}

\author{
José D. Castro $^{\mathrm{a}, *}$, E. Carneiro ${ }^{\mathrm{a}}$, S.M. Marques ${ }^{\mathrm{a}}$, Bruno Figueiredo ${ }^{\mathrm{b}}$, Antonio J. Pontes ${ }^{\mathrm{c}}$, \\ Álvaro M. Sampaio ${ }^{\mathrm{b}}$, Isabel Carvalho, ${ }^{\mathrm{a}, \mathrm{d}, \mathrm{e}}$, Mariana Henriques ${ }^{\mathrm{d}}$, Paulo J.S. Cruz ${ }^{\mathrm{b}}$, S. Carvalho ${ }^{\mathrm{a}, \mathrm{e}}$ \\ ${ }^{\text {a }}$ CFUM-UP, Centro de Física das Universidades do Minho e do Porto, University of Minho, Campus of Azurém, 4800-058 Guimarães, Portugal \\ ${ }^{\mathrm{b}}$ Universidade do Minho, Lab2PT, Escola de Arquitetura, Campus de Azurém, 4800-058 Guimarães, Portugal \\ ${ }^{\mathrm{c}}$ Universidade do Minho, Institute of Polymers and Composites, Campus de Azurém, 4800-058 Guimarães, Portugal \\ ${ }^{\mathrm{d}}$ CEB - Center of Biological Engineering, LIBRO - Laboratório de Investigação em Biofilmes Rosário Oliveira, University of Minho, Campus of Gualtar, 4710-057 Braga, \\ Portugal \\ ${ }^{\mathrm{e}}$ SEG-CEMMPRE Mechanical Engineering Department, University of Coimbra, 3030-788 Coimbra, Portugal
}

\section{A R T I C L E I N F O}

\section{Keywords:}

Additive manufacturing

Surface characterization

Decorative element

Antibacterial

Antibiofouling

\begin{abstract}
A B S T R A C T
Additive manufacturing (AM) is a hot topic nowadays, having a first order in importance in research trends, improving existent technologies and carrying them further. AM can be applied to ceramics, which have importance in current technologies. Their capability to maintain functional properties for long time periods, combined with the easiness to process and the abundance of raw materials, make them a fundamental part of mankind development. Within ceramics, stoneware has a wide range of uses but in some conditions, it can be affected by biofouling. $\mathrm{Ti}(\mathrm{O}) \mathrm{N}$ and $\mathrm{Ag}-\mathrm{Ti}(\mathrm{O}) \mathrm{N}$ coatings over 3D printed stoneware, were presented as multifunctional solution, linking aesthetical and antimicrobial properties. Films were developed by reactive direct current (DC) magnetron sputtering and characterized physical, chemical and morphologically, as well as regarding their colour variation. Moreover roughness, wettability, antibacterial and antibiofouling were also evaluated. The results revealed that the Ag doped coatings (with or without oxygen addition) had an enhanced multifunctionality compared to control samples (without Ag). Ag nanoparticles addition created a surface with potential antibacterial and antibiofouling activities, in order to resist outdoors and aqueous environments, making these films able to be applied in architectural pieces as sculptures or other decorative parts, maintaining their properties with good aesthetical properties.
\end{abstract}

\section{Introduction}

Additive manufacturing (AM) is a trend topic nowadays on research and innovation. AM could be understood like layer-by-layer building technique performed to obtain designed pieces with functional properties and optimized performance. Also, it will allow complex structures with lower times and decreasing energy costs to be realized [1]. This technology is adaptable and versatile because it can use various types of materials: metals, polymers, ceramics and compounds. Selective laser sintering (SLS), direct laser metal forming (DLMF), electron beam melting (EMB), stereolithography (SLA) or fused deposition modelling (FDM) are some AM technologies applied currently by many researchers and in some cases, on a commercial scale [2,3].

The advent of AM brought unprecedented possibilities in different areas, such as biomedicine, with sintered alloys and various polymers in implants, soft tissue replacements, drug deliveries, among others [2]; aerospace industry, in reduced volume parts and replacements parts for aircraft with advanced materials as aluminium alloys, titanium alloys, nickel super-alloys and special steels; automotive industry, in the development of some structural and engine parts; and tooling industry, like moulds with complex refrigeration systems enabling better performances and higher life time, [3].

Additive manufacturing, namely with metals and polymers, is no longer the future, it is the unavoidable present, but the additive manufacture of ceramic materials is still far from the desired maturity. Abundance, easy manipulation, low cost, heat resistance and long life time span are the main characteristics of ceramics [4] and across human history, new technologies have enlarged its uses. Chemically, ceramics can be considered as compounds formed between metallic and non-metallic elements with predominant ionic bonding but having a

\footnotetext{
* Corresponding author at: Departamento de Física, Escola de Ciências, Universidade do Minho, Alameda da Universidade, 4800-058 Guimarães, Portugal.

E-mail address: id8292@alunos.uminho.pt (J.D. Castro).
} 
covalent character [5]. Typically, traditional ceramics are made of clay and water, which is formed and dried later. Thus, some AM technologies have been adapted to use ceramics in some specialized and advanced applications as Wei et al. [6] that used SLS to form complex structural parts with $\mathrm{Si}_{3} \mathrm{~N}_{4}$, known by its good dielectric and mechanical properties. Unlike conventional methods to produce $\mathrm{Si}_{3} \mathrm{~N}_{4}$, it is possible to obtain ultra-high porosity with SLS, improving mechanical strength for possible post-treatments [6]. Other example could be the study developed by Dasan et al., where porous 3D printed akermanite scaffolds from silicones by direct ink writing and firing treatment, achieved some promising results, almost obtaining a crack-free and phase pure material [7]. These works are very far from ancient times, when first human civilizations, were using ceramics in common stuff as pottery or recipients. Probably, architecture is the most antique and major user of ceramics and nowadays, still has wide use in intelligent windows, glazed titles, constructions bricks, buildings and reinforced structures, opening new horizons and challenges for additive manufacturing using ceramics as base materials.

However, ceramics are not perfect and present problems or weakness in other aspects as stiffness, low toughness and high porosity. The last one, plays a crucial role promoting the biological attaching process when ceramics are exposed to outdoor conditions [8]. Among the biological agents studied are cyanobacteria, lichens, mosses, algae and fungi [4]. All these agents can provoke a decay in aesthetic appearance, which are key aspects in some ceramics' applications as architectural pieces and artworks. In this context, several studies established the influence of geographic location and climate aspects as important facts to consider in the characterization of biofilms in nature [4].

Obviously, biological agents' attachments (better known as biofouling) on ceramics surfaces means high maintenance costs, and, additionally in cases where pieces are considered as cultural heritage, the maintenance cost or a possible restoration can be incommensurable. For instance, Ortega et al. [9] performed a study about how cyanobacteria attached to the walls of two cathedrals (Spain and Sweden), promoting physical harm. Across observations, authors noted that the walls exhibited significant damage with grains detaching, and in some parts, up to some millimetres into the walls. The authors demonstrated as cyanobacterial-algal communities damaged the walls owing to the high porosity of the stone that composed the walls, keeping always humidity caught inside it, and so facilitating the biofilm growth. In addition, Bastian et al. [10] performed a study on how microbiology affected the Lascaux cave (France). The algae and fungi biofilms were formed in ceiling and walls respectively influenced by arthropods and human intervention, causing a potential damage in Palaeolithic paintings found inside the cave. But not only cultural heritages have been studied, Assets as private houses have been studied too as the case of Ettenauer and collaborators [11].

In order to preserve good conditions on ceramics surfaces, process as glazing, cooking or coatings are widely used and in the latter case, painting is the most common protection procedure applied as a finishing stage for its availability, ease of application and relative low cost. However, when we are talking about biofouling, paints do not avoid it altogether and it is necessary to apply some more advanced surface modification's technologies. Recent studies have tried to find some solutions for this problem applying photocatalytic layers [12,13], "cool" paints [14-16], silica-containing paints [17] and silver nanoparticles suspension [18]. These techniques have been applied on ceramics trying to contribute against climate changes and finding sustainable built processes to obtain multifunctional coatings and enlarge possibilities for new uses. In future scenarios, self-cleaning behaviour, antibiofouling and outdoor conditions resistance are always searched in order to maintain materials integrity, reducing maintenance costs. In addition to the mentioned topics, aesthetic properties are also a quite important point for the architectural field.

Therefore, the present study aims to obtain a coating that incorporates all the desired properties and additionally, can be simply customised with a significative colour variation in 3D printed stoneware samples, using a physical vapor deposition technique in order to achieve the desired multifunctionality (aesthetic and antibiofouling) for potential architectural pieces. It is important to highlight the importance of the current study since it opens the possibility of integrating a PVD process and additive manufacturing technologies (as 3D printing) in order to obtain a higher performance in ceramic pieces, which is possibly applicable to other substrates. Other studies were focused in obtaining antibiofouling properties in marine applications $[19,20]$, medical implants [21,22] or water treatments [23], until now, none has studied how to integrate aesthetic and antibiofouling properties as part of a multifunctional applied solution.

\section{Experimental}

The coatings were developed by direct current (DC) magnetron sputtering technique, using a reactive atmosphere of $\mathrm{Ar}+\mathrm{N}_{2}+\mathrm{O}_{2}$. The Ti and Ag targets $\left(200 \times 100 \mathrm{~mm}^{2}\right)$ are vertically aligned in opposed position arranged in closed field configuration with a substrate holder placed under rotation $(7 \mathrm{rpm})$ in the centre at $70 \mathrm{~mm}$ distance. All films were sputtered onto stainless steel 316L, (100) silicon wafer and $3 \mathrm{D}$ printed stoneware 130-MP. The substrates were cleaned in distilled water, acetone and ethanol sequentially for $10 \mathrm{~min}$ in an ultrasonic bath in order to remove any impurity or contamination. After ultrasonic cleaning, stoneware samples were heated at $100{ }^{\circ} \mathrm{C}$ for $1 \mathrm{~h}$ to remove any absorbed humidity. Additionally, prior to coating deposition, substrates were cleaned by etching with an argon plasma $(75 \mathrm{sccm}$ Ar flow rate) for $15 \mathrm{~min}$, using a pulsed direct current power source at $0.3 \mathrm{~A}, 1536 \mathrm{~ns}$ reverse time and $200 \mathrm{kHz}$ pulse frequency.

Two sets of coatings were deposited in the present study: set $1-$ TiN based system with oxygen addition in order to obtain different colours; set $2-\mathrm{Ag}$-TiN based system with oxygen addition to obtain multifunctional coatings with colour variation and biofouling resistance with the inclusion of silver nanoparticles inside the film or over the top layer. To achieve proposed coatings in the sputtering process, reactive atmosphere and some parameters were varied according to the schematic representation shown in Fig. 1 and Table 1, and taking account the silver content cannot raise up 5 at.\% in order do not degrade the mechanical properties as achieved in previous results [24,25]. During deposition, the temperature and the base pressure were kept constant at $450 \mathrm{~K}$ and around $4 \times 10^{-4} \mathrm{~Pa}$, respectively. For silver containing films the current density applied to the Ti target was $10 \mathrm{~mA} / \mathrm{cm}^{2}$ and to the Ag target $0.6 \mathrm{~mA} / \mathrm{cm}^{2}$. While the Ti target was connected to a direct current power supply, the Ag target was operated with a pulsed direct current power supply at a frequency of $200 \mathrm{kHz}$ and a reverse time of 1536 ns. For Ti(O)N, and Ag-Ti(O)N coatings, an additional TiN interlayer was deposited for $5 \mathrm{~min}$ before the final film. For $\mathrm{O}_{2}$ addition in a controlled manner, a reactive gas pulsing process (RGPP) controlled by software was used, wherein is possible set different duty cycles in order to avoid poisoning. The duty cycle used in this work was already well described in previous studies [26-30]. To perform oxygen pulses in cyclic waves into the deposition chamber, it was modified the cycle period $\left(\mathrm{T}=\mathrm{t}_{\mathrm{ON}}+\mathrm{t}_{\mathrm{OFF}}\right.$ ) and the signal shape in order to achieve the desired characteristics. According with Carvalho et al. [31], the duty cycle percentage $(\alpha)$ will be equal to the time when the signal is at the maximum flow allowed $\left(\mathrm{t}_{\mathrm{ON}}\right)$ divided by the cycle period $\left(\alpha=\mathrm{t}_{\mathrm{ON}} / \mathrm{T}\right)$. For the present study, was used a $45 \mathrm{~s}$ period in a square wave. $\mathrm{O}_{2}$ duty cycle set-ups were 40 and $80 \%$ (corresponding to toN equals to 18 and $36 \mathrm{~s}$ respectively), meaning that the oxygen flowing towards the chamber was present in the sputtering process just in a percentage of deposition time. In both sets, the minimum oxygen intake $\left(\mathrm{q}_{\min }\right)$ allowed in duty cycle was $0 \mathrm{sccm}$. The maximum oxygen flows $\left(\mathrm{q}_{\max }\right)$ and times are exposed in Table 1.

The film morphology as well as film thickness and the chemical composition have been measured on films deposited on Si substrates in the same deposition run using a FEI Nova 200 scanning electron 


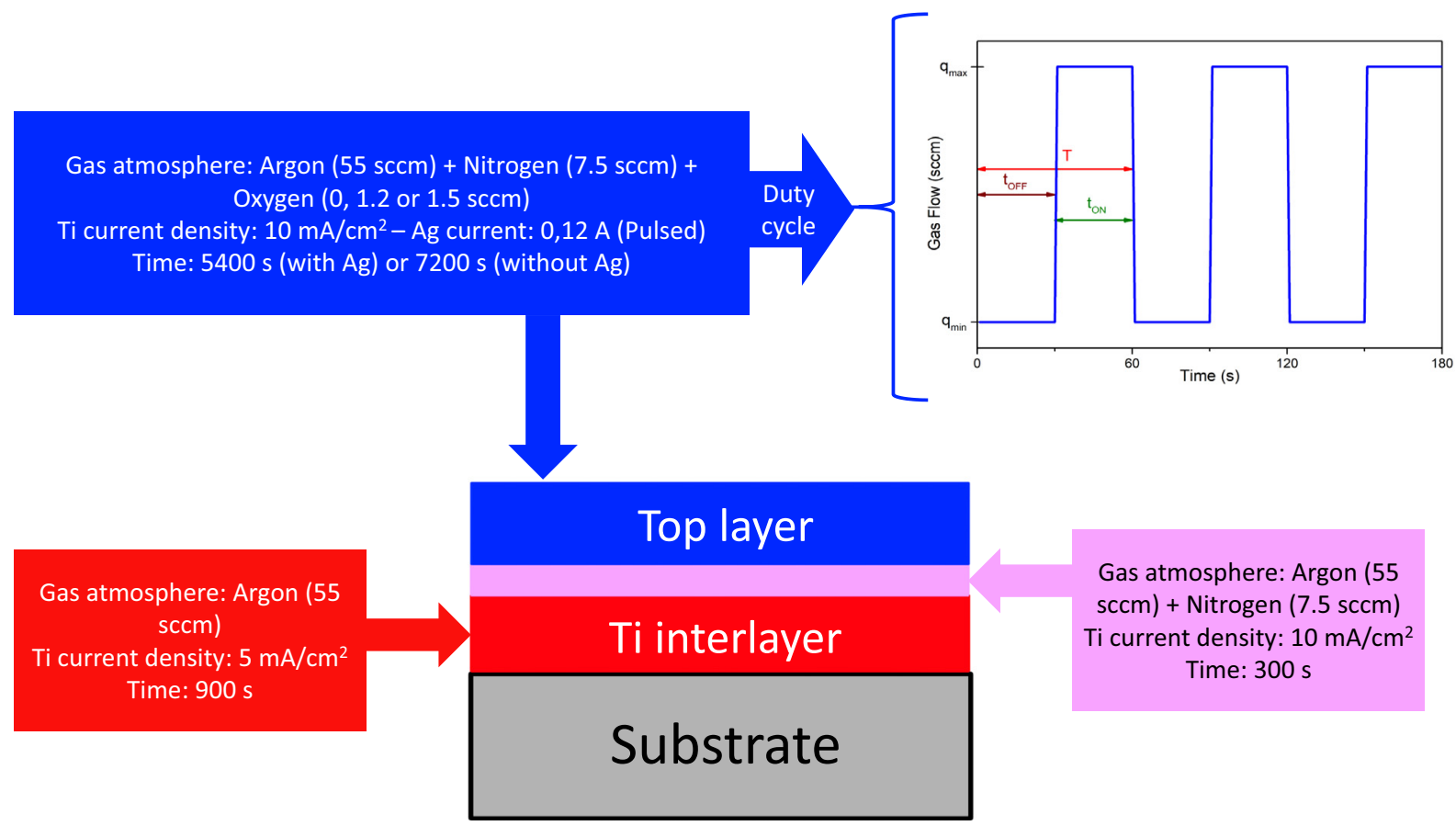

Fig. 1. Schematic representation and parameters of deposited films.

microscope (SEM) equipped with an EDAX Pegasus X4M detector for energy-dispersive X-ray spectroscopy (EDS) at $15 \mathrm{kV}$ and a working distance of $5 \mathrm{~mm}$.

Three measurements were taken on each obtained coating to assess the surface uniformity. All SEM micrographs were processed in ImageJ software and each length or diameter measure was made 10 times in order to obtain a consistent value.

Phase configuration and structures on coatings were assessed by Xray diffraction (XRD) in a Bruker D8 Discover with CuKa $\left(\lambda=1.5406 \AA\right.$ ) radiation operated at $40 \mathrm{kV}$ and $40 \mathrm{~mA}$ with $0.04^{\circ}$ step size on 316L stainless steel substrates. Pseudo-Voigt function was used to fit all measurements, obtaining the full width at half-maximum (FWHM) for grain size calculations by Scherrer formula.

Ceramic samples with coatings were submitted to colour study in the CIE L*a*b* colour space with a commercial MINOLTA CM-2600d portable spectrophotometer under the standard CIE illuminant D65. The obtained measurements (average of 3 measurements) were displayed in the 1976 CIE L*a*b* colour space. Also, wettability behaviour was assessed on Dataphysics OCA20 equipment. The water contact angle (WCA) was measured using a $2 \mu \mathrm{l}$ syringe with ultrapure water $(99,99 \%)$ at room temperature. Also, samples roughness was estimated through atomic force microscopy (Icon Dimension, Bruker) with a conductive Si cantilever in the contact mode. The average roughness (Ra) was obtained after three independent measurements, holding a $2.5 \times 2.5 \mu \mathrm{m}^{2}$ area. The antibacterial activity of obtained coatings was tested against Staphylococcus epidermidis (ATCC 12228 obtained from American Type Cell Collection). Zone of Inhibition tests, adapted from Kirby-Bauer method [32], were performed to evaluate the antibacterial activity of samples. Initially, the inoculation of a single colony was carried out in $20 \mathrm{ml}$ Tryptic soy broth (TSB, Merck) culture and incubated at $37{ }^{\circ} \mathrm{C}$ overnight at $120 \mathrm{rpm}$. The cell suspension obtained was adjusted to an optical density (OD) of 0.8 at $620 \mathrm{~nm}$ and properly diluted in culture media to $1 \times 10^{6} \mathrm{CFU} / \mathrm{ml}$. An aliquot of cellular suspension $(300 \mu \mathrm{l})$, was spread in Tryptic Soy Agar (TSA, Merck) petri dishes. After medium solidification, the samples (previously sterilized by exposure of $\pm 1 \mathrm{~h}$ to UV light) were placed separately on the top of the agar plate, placing the side with treatment in contact with the agar and incubated for $24 \mathrm{~h}$ at $37{ }^{\circ} \mathrm{C}$. After the incubation period, the halo (zone of transparent medium, which means that there is no bacteria growth) formed around the sample was measured and photographed to record the results (images captured with Image $\mathrm{Lab}^{\mathrm{TM}}$ software). All experiments were repeated in at least three independent assays.

Antibiofouling test was performed in a medium prone to biofouling formation. Water from an aquarium with fishes and without additional cleaning (e.g. filtering or chemically cleaning) was removed every week (half of the total volume, which was replaced by fresh water in the aquarium) and placed in 6 well-plates containing the samples as shown Fig. 2 (every time, half on the volume $(2 \mathrm{ml})$ was removed and the new amount of water from the aquarium was placed). The experiment lasted 2 months. Later, the samples were carefully washed three times in distilled water and dehydrated by immersion in increasing ethanol concentration solutions with 70,95 and $100 \%(\mathrm{v} / \mathrm{v})$ for 10,10 and 20 min respectively, and placed in a sealed desiccator. Afterwards, the samples were mounted on aluminium stands with carbon tape, sputter coated with gold and observed with a NanoSEM - FEI nova200 equipment. In order to assess the extent of biofouling formation in each

Table 1

Layers applied for all depositions on present study.

\begin{tabular}{|c|c|c|c|c|c|}
\hline & Top layer & $\mathrm{Ti}$ interlayer & TiN interlayer & O2 flow & Duty cycle time \\
\hline Set 1 & TiN & $\checkmark$ & $x$ & $\times$ & $x$ \\
\hline \multirow[t]{2}{*}{$\operatorname{Ti}(\mathrm{O}) \mathrm{N}$} & TiON-DC40 & $\checkmark$ & $\checkmark$ & $\checkmark(1.5 \mathrm{sccm})$ & $18 \mathrm{~s}$ \\
\hline & TiON-DC80 & $\checkmark$ & $\checkmark$ & $\checkmark(1.5 \mathrm{sccm})$ & $36 \mathrm{~s}$ \\
\hline Set 2 & Ag-TiN & $\checkmark$ & $\checkmark$ & $\times$ & $x$ \\
\hline \multirow[t]{2}{*}{$\mathrm{Ag}-\mathrm{Ti}(\mathrm{O}) \mathrm{N}$} & Ag-TiON-DC40 & $\checkmark$ & $\checkmark$ & $\checkmark(1.2 \mathrm{sccm})$ & $18 \mathrm{~s}$ \\
\hline & Ag-TiON-DC80 & $\checkmark$ & $\checkmark$ & $\checkmark(1.2 \mathrm{sccm})$ & $36 \mathrm{~s}$ \\
\hline
\end{tabular}



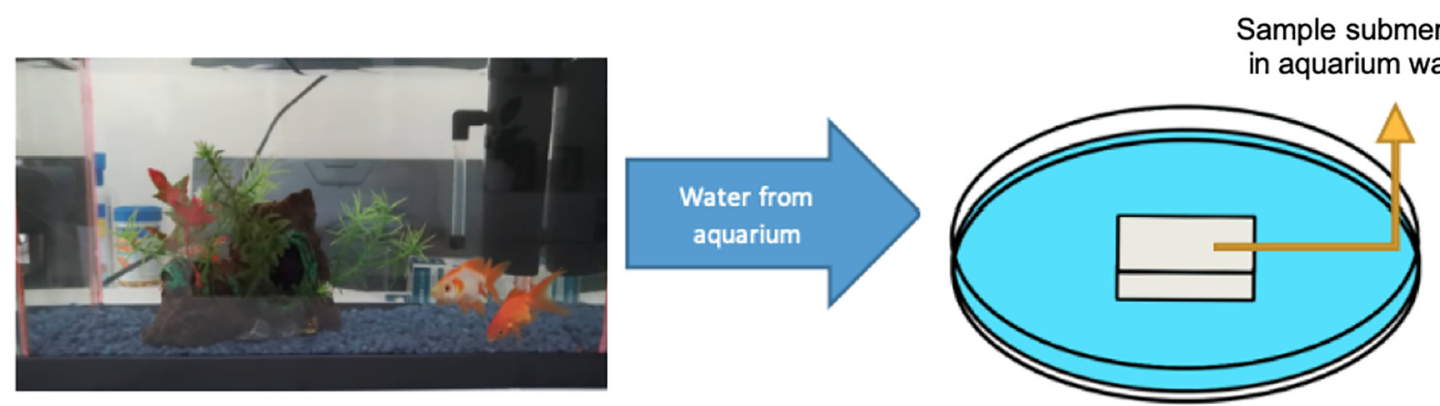

Fig. 2. Representation of biofouling tests.

Table 2

Composition of the samples obtained corresponding to every deposition set-up.

\begin{tabular}{|c|c|c|c|c|c|c|c|}
\hline & Sample name & Color & $\begin{array}{c}\mathrm{Ti} \\
\text { (at. \%) }\end{array}$ & $\begin{array}{c}\mathbf{N} \\
\text { (at. \%) }\end{array}$ & $\begin{array}{c}0 \\
\text { (at. \%) }\end{array}$ & $\begin{array}{c}\mathbf{A g} \\
\text { (at. \%) }\end{array}$ & $\begin{array}{l}\mathrm{O} / \mathrm{N} \\
\text { ratio }\end{array}$ \\
\hline \multirow{3}{*}{$\begin{array}{l}\text { Set } 1 \\
\text { Ti(O)N }\end{array}$} & TiN & & $52 \pm 0.26$ & $48 \pm 0.62$ & - & - & - \\
\hline & TION-DC40* & & $49 \pm 0.25$ & $29 \pm 0.48$ & $22 \pm 0.66$ & - & 0.76 \\
\hline & TiON-DC80** & & $48 \pm 0.26$ & $14 \pm 0.36$ & $38 \pm 0.83$ & - & 2.71 \\
\hline \multirow{3}{*}{$\begin{array}{c}\text { Set } 2 \\
\text { Ag-Ti(O)N }\end{array}$} & Ag-TiN & & $52 \pm 0.25$ & $45 \pm 0.61$ & - & $3 \pm 0.07$ & - \\
\hline & Ag-TiON-DC40* & & $45 \pm 0.23$ & $27 \pm 0.44$ & $28 \pm 0.67$ & $1 \pm 0.04$ & 1.04 \\
\hline & Ag-TiON-DC80** & & $44 \pm 0.24$ & $17 \pm 0.37$ & $38 \pm 0.77$ & $1 \pm 0.04$ & 2.23 \\
\hline
\end{tabular}

*Duty cycle $40 \%$.

**Duty cycle $80 \%$.

sample, three fields were used for image analysis.

\section{Results and discussion}

\subsection{Chemical and morphology characterization}

Regarding to the chemical composition, Table 2 shows a resume of the films composition through EDS analysis. The results depicted that as expected increasing the duty cycle (DC) on the $\mathrm{O}_{2}$ flux, it is possible to increase the oxygen content and obviously decrease the nitrogen content for both sets of samples (example, compare TiON-DC40 with TiONDC80). In regard to silver addition (set 2), a maximum of 3 at.\% was reached. Regarding the Ag-Ti(O)N films, no a meaningful silver variation was observed related to an $\mathrm{O} / \mathrm{N}$ ratio increase.

Through the deposition time and coatings thickness, estimated by SEM analysis, it was possible to determine the deposition rate (Table 3). One aspect that can be highlighted is that the deposition rate is clearly increased with addition of silver on the coatings, even for very low atomic content. Since Ag show higher sputtering yields comparing with $\mathrm{Ti}$ (3.12 and 0.51, when bombarded with Ar at $0.5 \mathrm{keV}$, respectively [33]), the deposition of this element results in higher deposition rates.

The top-view and cross-section morphologies of the Ag-Ti(O)N coatings are presented in Fig. 3a)-f) as sections I and II, respectively.

Table 3

Thickness and deposition rates of achieved coatings over Si (100) wafers.

\begin{tabular}{cllll}
\hline & $\begin{array}{l}\text { Sample } \\
\text { name }\end{array}$ & $\begin{array}{l}\text { Interlayer } \\
\text { thickness } \\
(\mu \mathrm{m})\end{array}$ & $\begin{array}{l}\text { Total thickness } \\
(\mu \mathrm{m})\end{array}$ & $\begin{array}{l}\text { Deposition rate } \\
(\mu \mathrm{m} / \mathrm{h})\end{array}$ \\
\hline Set 1 & TiN & 0.08 & $0.7 \pm 0.1$ & 0.4 \\
Ti(O)N & TiON-DC40 & - & $0.8 \pm 0.1$ & 0.4 \\
& TiON-DC80 & 0.10 & $1.2 \pm 0.1$ & 0.5 \\
Set 2 & Ag-TiN & 0.17 & $2.3 \pm 0.2$ & 1.3 \\
Ag-Ti & Ag-TiON- & 0.24 & $1.7 \pm 0.2$ & 0.9 \\
$(\mathrm{O}) \mathrm{N}$ & DC40 & & & \\
& Ag-TiON- & 0.20 & $1.8 \pm 0.1$ & 1.0 \\
& DC80 & & &
\end{tabular}

The Ti(O)N coatings' surface has flake-shaped mounds with few column border definitions for low $\mathrm{O}_{2}$ flow rates (low duty cycle). For higher oxygen content, the films become denser and with a decrease on the roughness. This trend is similar as expected for both sets, even if with silver incorporation densification becomes less evident or even retarded. In fact, Ag-TiN coating presents three-sided pyramidal shaped grains, uniformly on a more open surface, induced by the grow of a second silver phase. For samples with silver and high oxygen content it is possible to see the presence of $\mathrm{Ag}$ clusters and some aggregates on the surface as it has been reported in other studies [34-36]. The formation of $\mathrm{Ag}$ nanoparticles is related to the immiscibility of $\mathrm{Ag}$ in the $\mathrm{Ti}(\mathrm{O}) \mathrm{N}$ matrix. It was reported for Lopes et al. [37] that $\mathrm{Ag}-\mathrm{TiN}_{\mathrm{x}}$ coatings were composed of Ag clusters segregated from the TiN cubic grain boundaries, which appear as bright spots in the SEM micrographs. Several authors have reported that silver clusters are able to diffuse in the base coating, which leads to a non-uniform Ag distribution along the coating thickness. In order to clarify these findings, the morphology of the coatings was analyzed by cross-sectional SEM micrographs of fractured samples. The cross-section of the samples shows a columnar-type structure common in this type of films with relative low deposition temperature according with Thornton diagram [38], even with a densification promoted with the oxygen incorporation. All depositions with $\mathrm{Ag}$, presented nanoparticles in the boundaries of the columns quite well distributed along the coating thickness. Other important fact revealed by the cross-section images was the accommodation of Ag nanoparticles in the Ag-TiN coatings, embedded uniformly across the film. This accommodation in the film could be the cause of the dramatical change in the coating growth, promoting the non-uniform top profile sighted in the Fig. 3 section II e).

\subsection{Structural analysis}

XRD analysis was performed in order to understand the evolution of the structure with the incorporation of oxygen and silver elements on the TiN base matrix. The XRD patterns are presented in Fig. 4 and the reference peaks were obtained from the International Centre for Diffraction Data (ICDD) database and the main crystalline phase was 


\section{Oxygen increasing}

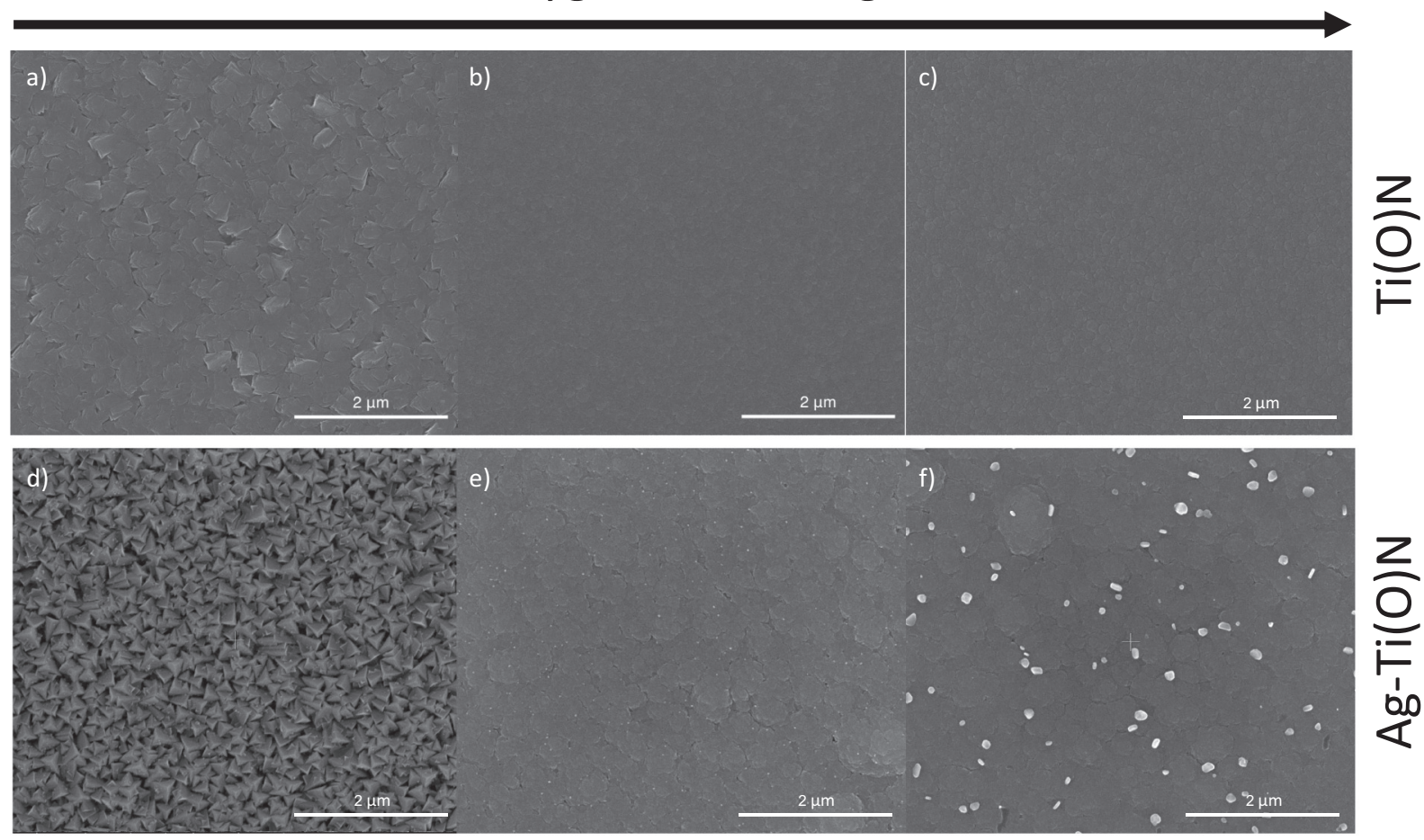

\section{Oxygen increasing}
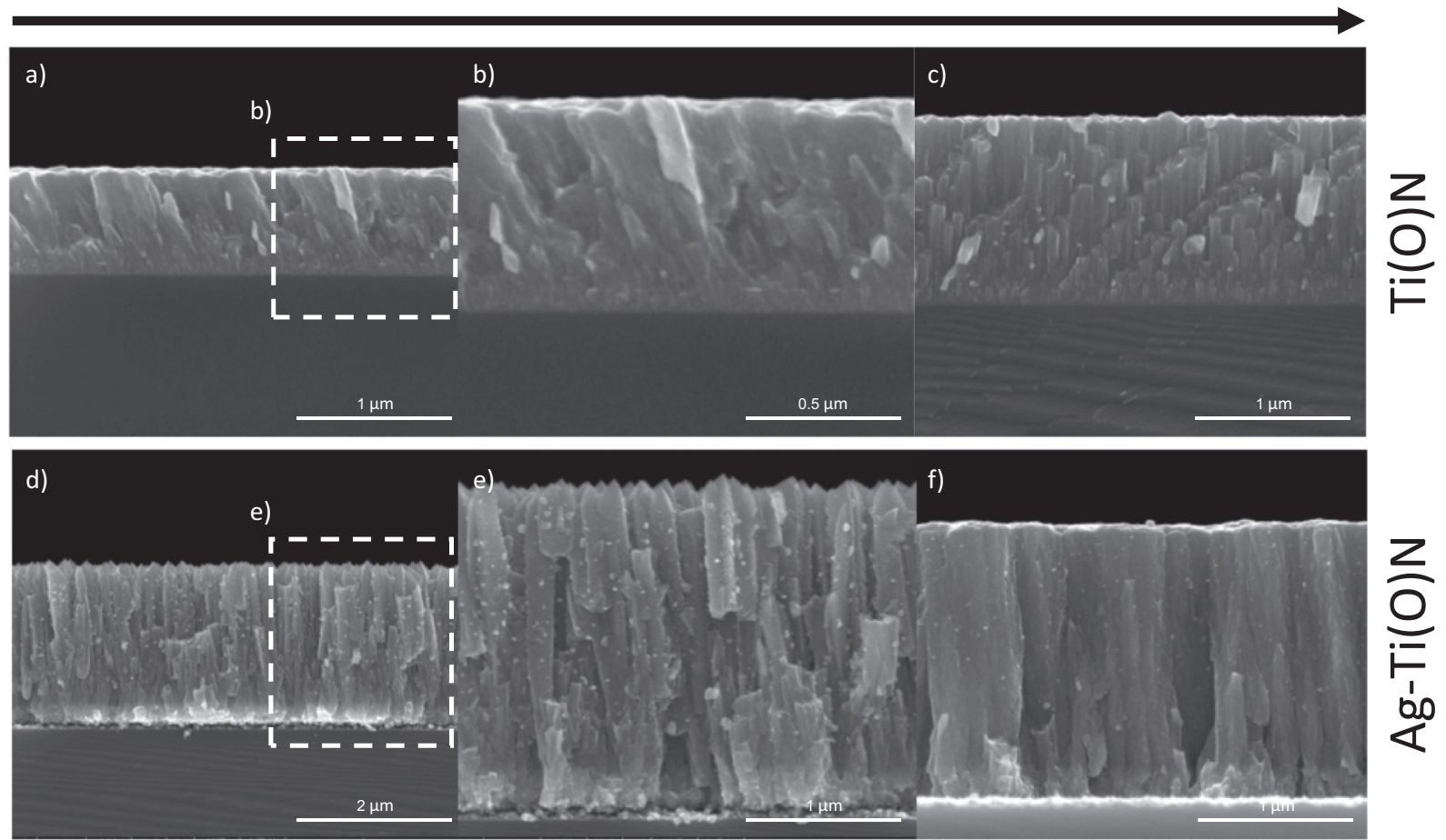

Fig. 3. Section I. SEM top-view images as function of the Oxygen increase and also with silver incorporation. a) TiN, b) TiON-DC40, c) TiON-DC80, d) Ag-TiN, e) AgTiON-DC40, f) Ag-TiON-DC80.

Section II. SEM cross-section images as function of the oxygen increase and also with silver incorporation. a) TiN, b) TiN surface profile detail denoted in the zone from image a), c) TiON-DC80, d) Ag-TiN, e) Ag-TiN surface profile detail denoted in the zone from image d), f) Ag-TiON-DC80.

identified with the pattern no. 00-038-1420 (titanium nitride). The differences in chemical composition correlate well with the differences observed in the developed structure. It is important to highlight that no significative changes were observed for intermediate oxygen contents, in agreement also with functional properties. TiN based coatings (with or without Ag) showed the typical peaks from (111), (200), (220) and (311) planes characteristics of rock-salt (face cubic centred) structure as has been reported on previous works about this system [30,39-44]. Also, a Ti peak was noticed from (002) plane according the pattern no. 00-051-0631, that corresponds to the adhesion interlayer. 

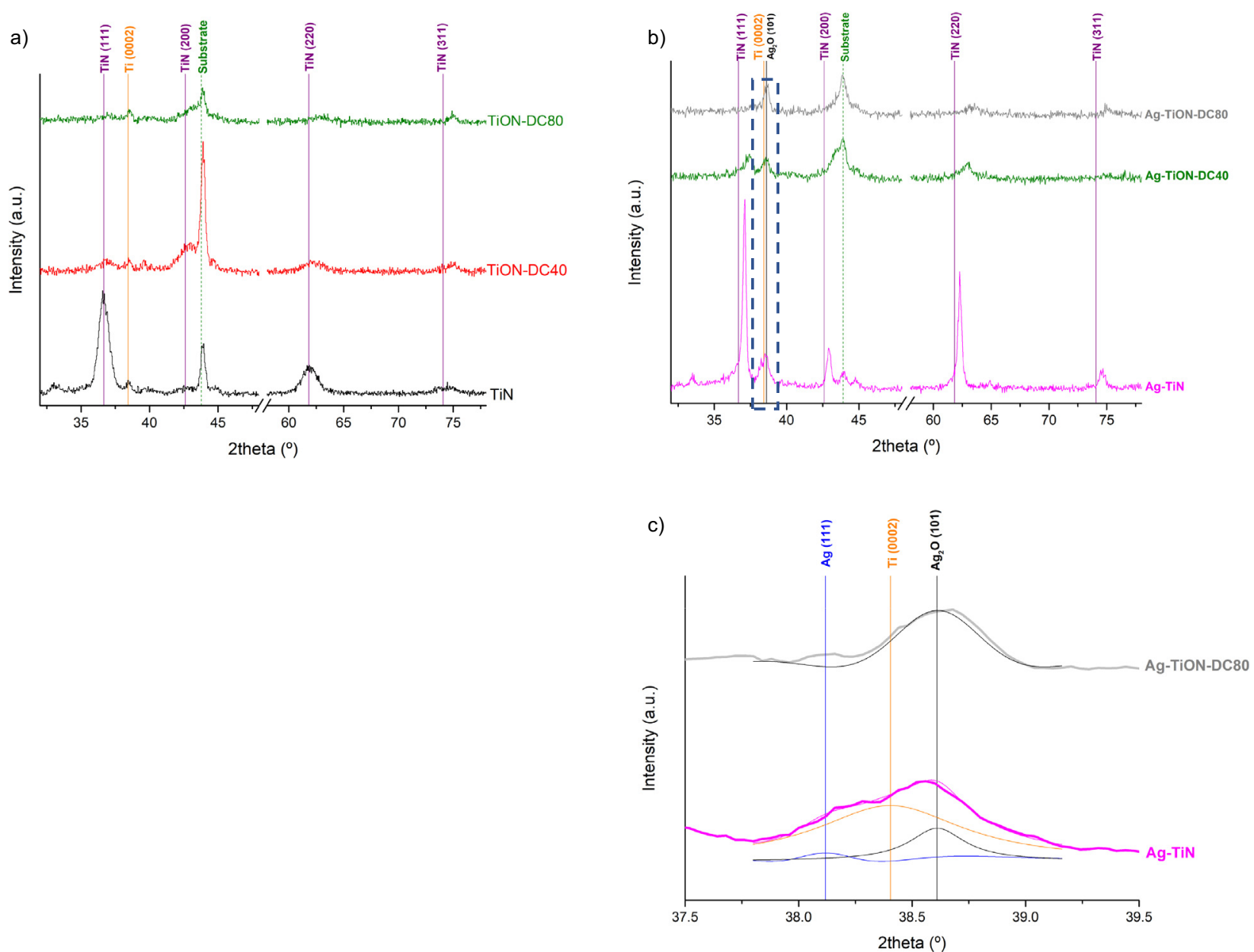

Fig. 4. XRD patterns obtained from developed films. a) $\mathrm{Ti}(\mathrm{O}) \mathrm{N}, \mathrm{b}) \mathrm{Ag}-\mathrm{Ti}(\mathrm{O}) \mathrm{N}$, and c) $\mathrm{Ag}-\mathrm{Ti}(\mathrm{O}) \mathrm{N}$. Inset denoted in image b) displaying Ag phases.

Fig. 4a) displays the structural evolution of TiN coatings with $\mathrm{O}$ addition. The decrease on the peaks' intensities with oxygen addition could be interpreted as a crystallinity loss on films, turning to an amorphous structure [30]. Comparing TiN and TiON-DC40 films, lattice parameter decreased from $0.422 \mathrm{~nm}$ to $0.419 \mathrm{~nm}$, which means a structure contraction by oxygen substitution on TiN lattice [30]. Also, applying the Scherrer formula to the TiN (111) plane reflections, the grain size was $10 \mathrm{~nm}$ for the TiN film and with the oxygen incorporation, this value decreased to $5 \mathrm{~nm}$ in TiON-DC40 film. As the $\mathrm{O}_{2}$ flow was rising, the peaks displayed on diffractograms corresponded to substrate, confirming the crystallinity loss aforementioned. The samples with silver incorporation (Fig. 4b) also exhibit a polycrystalline structure typical TiN structure reflection on abovementioned planes. In the Ag-TiN film, it can be observed a slight shift to $2 \theta$ higher positions in TiN peaks that could be promoted by a residual oxygen content into the coating. Unlike $\mathrm{Ti}(\mathrm{O}) \mathrm{N}$ films, Ag doped coatings shown a substantial rising in $38^{\circ}$, so that it was performed an inset in this position displayed in Fig. 4c). According with the inset, in the Ag-Ti(O)N films were found a sum of some silver phases peaks in closer positions. FCC-Ag (111) and $\mathrm{Ag}_{2} \mathrm{O}$ (101) peaks were noticed regarding to ICDD patterns 00-0040783 and 00-019-1155 respectively. Despite the low content, it can be noticed the evolution of silver into Ag doped films with the oxygen incorporation. As oxygen content was rising, Ag (111) plane peak decays up to be imperceptible in the Ag-TiON-DC80 coating and migrating to a more stable phase, $\mathrm{Ag}_{2} \mathrm{O}$. In fact, the appearance of $\mathrm{Ag}_{2} \mathrm{O}$ phase in $\mathrm{Ag}-\mathrm{Ti}(\mathrm{O}) \mathrm{N}$ films is coherent with the results found by Ferreri et al. [35], where they achieved antibacterial activity in Ag-ZrCN coatings and their XPS spectra disclose the presence of silver oxides in the surface of these films. This fact could be meant a shift in the functional behaviour against bacteria, as it will be discussed later.

\subsection{Roughness and wettability}

Wettability of the coatings to water (WCA) in room temperature its average roughness $(\mathrm{Ra})$ and root mean square roughness $(\mathrm{Rq})$ are summarized in Fig. 5 sections I and II. The stoneware without any coating was considered as control.

Roughness measurements were performed on the Ti(O)N films displayed a reduction of surface roughness parameter in order to be near to hydrophobic behaviour in TiON-DC80 coating. Also, in the AFM images can be noted, like aforementioned in morphology characterization (Fig. 3 section I), the evolution of the compactness when the oxygen incorporation was rising. In the $\mathrm{Ag}-\mathrm{Ti}(\mathrm{O}) \mathrm{N}$ samples exhibited a significant increasing in surface roughness parameters up to achieve a superhydrophilic surface and with the oxygen incorporation, surface turned more compact like the $\mathrm{Ti}(\mathrm{O}) \mathrm{N}$ system. According with these results, silver promoted an increase on the roughness due first, to the presence of silver nanoparticles on the surface of the thin film and second, to formation of an open morphology as can be noted in Fig. 5 section II. The dense samples show a decrease in the roughness (TiONDC80 and Ag-TiON-DC80). Both tendencies were confirmed by the SEM images.

According to the Wenzel model, water drops cover vacancies caused by irregularities on surface and promote a quick "absorption", unlike Cassie-Baxter model that contemplate air entrapments among drop and surface irregularities $[45,46]$. The first model is better to explain what happened on surfaces for this study because the major part of the obtained coatings was hydrophilic and according to the Wenzel model, the 

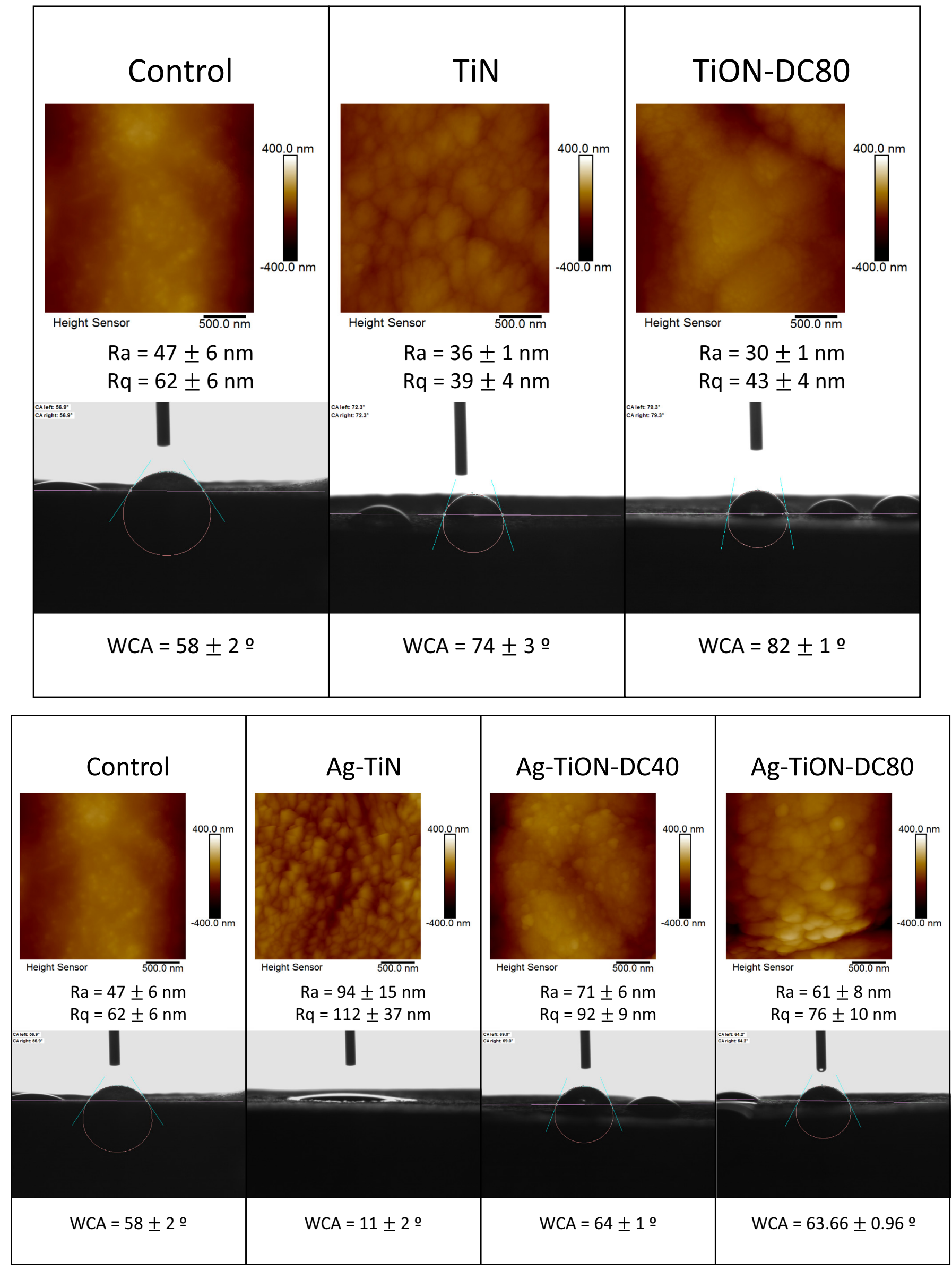


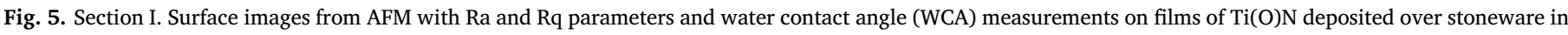
coatings.

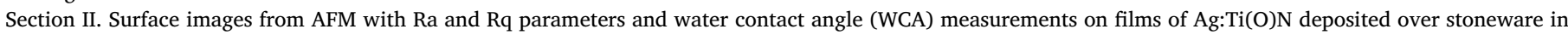
coatings.

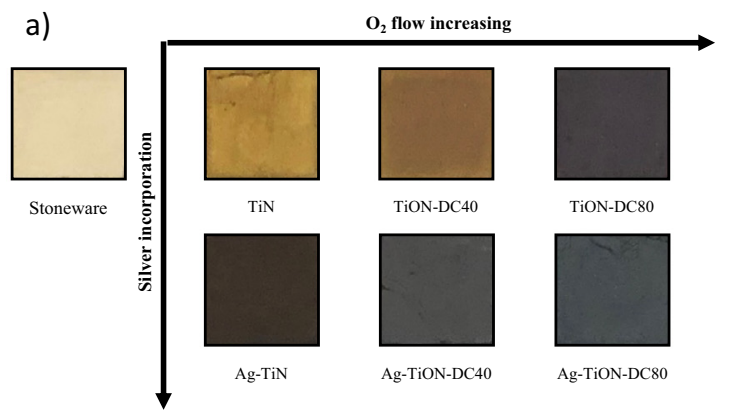

b)

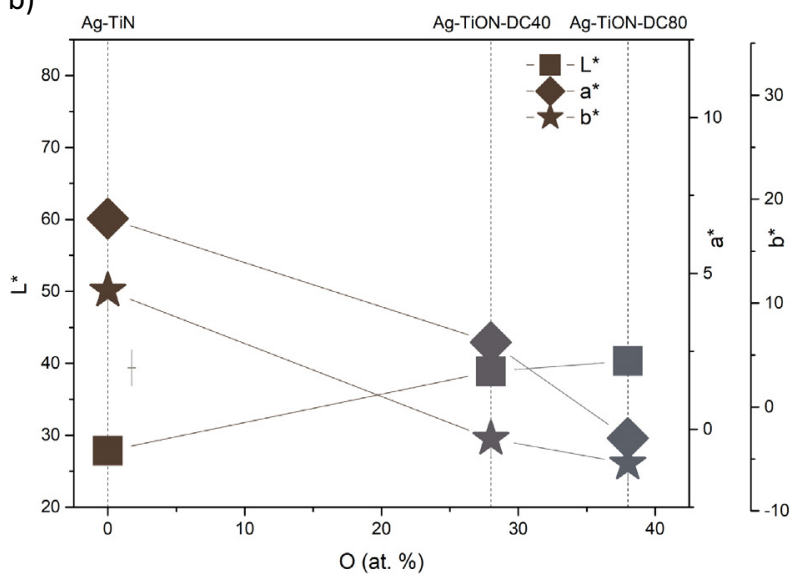

c)

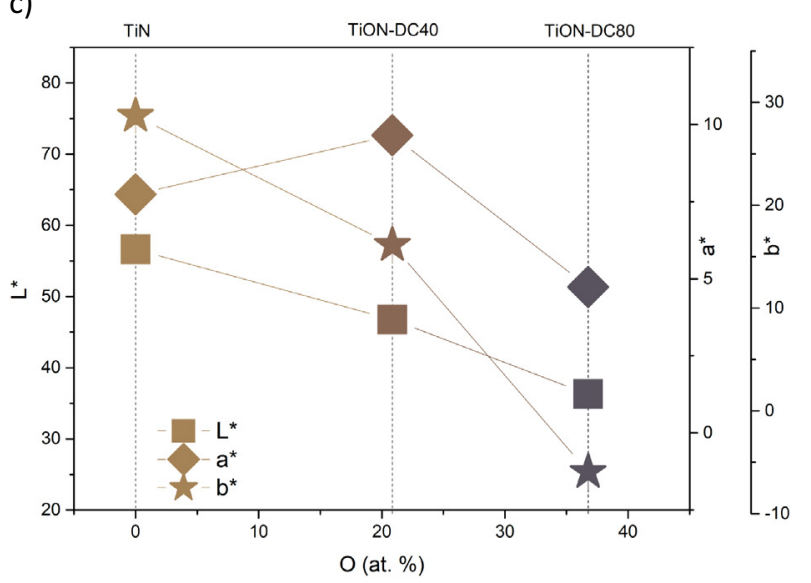

Fig. 6. Obtained colours over stoneware of all coatings according reactive gas flows with or without Ag doping (A) and colorimetric parameters of TiN (B) and Ag:TiN (C) systems as function of Oxygen atomic percentage content.

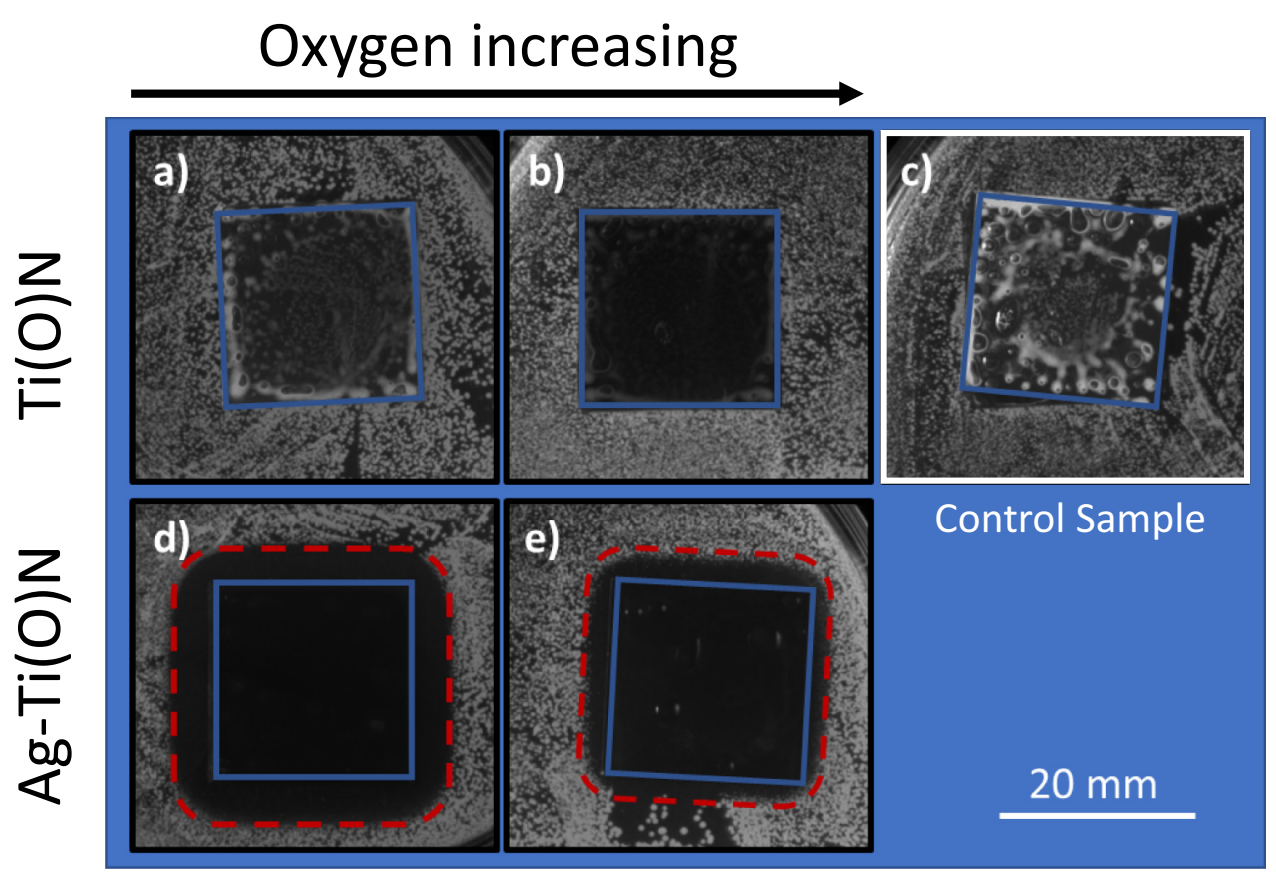

Fig. 7. Halo test performed with Staphylococcus epidermidis. Blue squares correspond to each sample and red dashed squares exhibit the inhibition zones by the formed halo. a) TiN, b) TiON-DC80, C) Control sample, d) Ag-TiN and E) Ag-TiONDC80. (For interpretation of the references to colour in this figure legend, the reader is referred to the web version of this article.) 


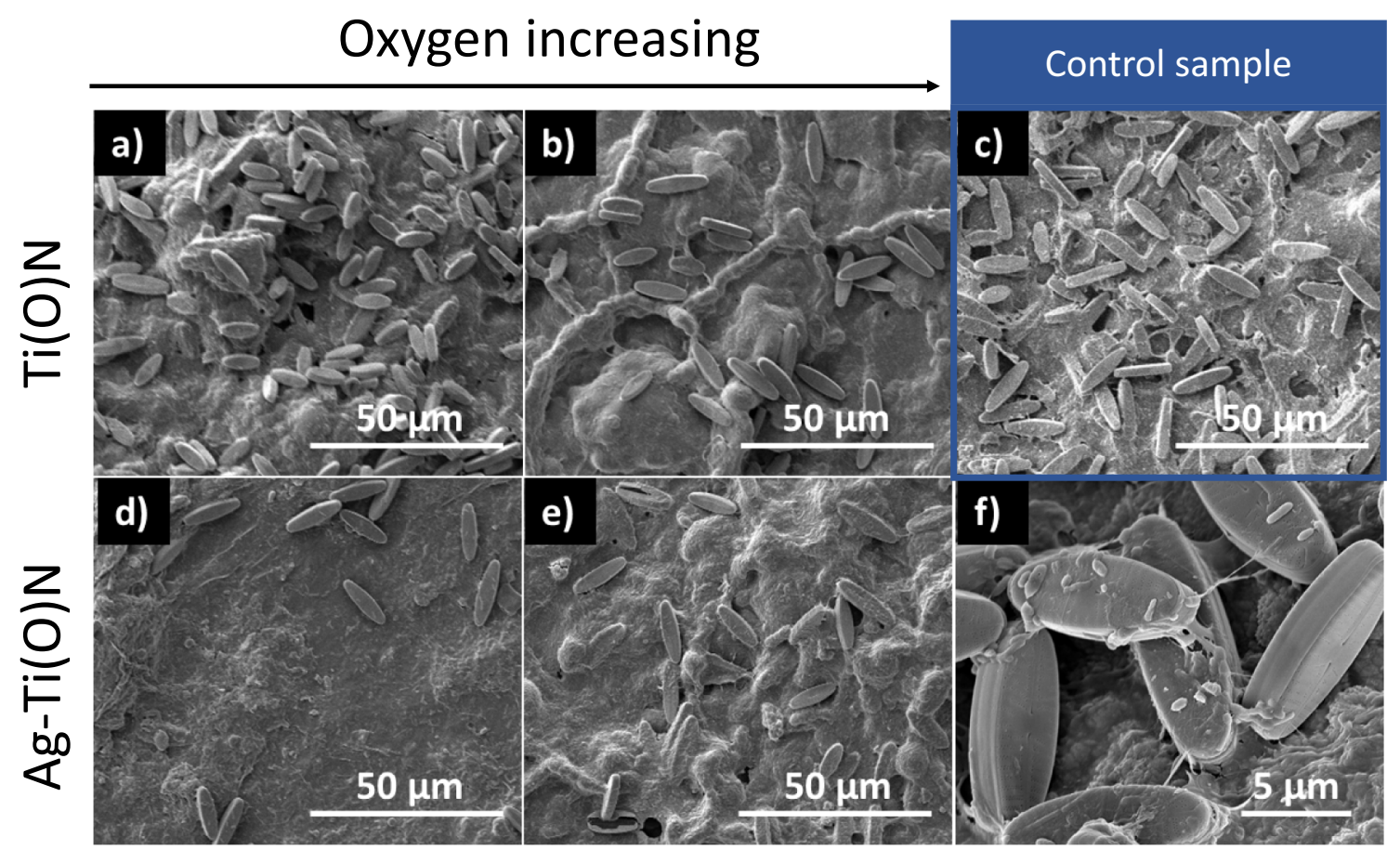

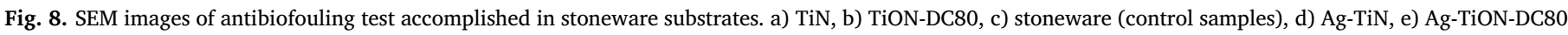
coatings and f) magnification of diatoms found (the great oval shapes) on surfaces.

mechanism for this behavior correspond to the drop spreading on all surface irregularities without let air stay caught between drop/sample interface. As it is well known, a hydrophilic surface has a strong affinity to water, otherwise a hydrophobic surface always will try to repel water [47]. According some authors [45,47-50], the surface nature correspond to specific WCA range values. A surface could be considered as superhydrophobic when its WCA is higher than $150^{\circ}$, hydrophobic when the WCA is among $90^{\circ}$ and $150^{\circ}$, hydrophilic when the WCA is among $10^{\circ}$ and $90^{\circ}$ and the last one, superhydrophilic when the surface has a WCA $<10^{\circ}$.

In the set 1 , it is possible to confirm that the stoneware surface wettability is not significantly influenced by the coatings. In fact, the stoneware generally is considered hydrophilic (WCA $<60^{\circ}$ ) and almost all coatings show a moderate hydrophilic character $\left(60^{\circ}-90^{\circ}\right)$, where the oxygen addition promotes slightly a higher water repellence (TiON-DC80 - WCA $85^{\circ}$ ).

Although, a strong decrease in the water contact angle from $75^{\circ}$ (TiN) down to $10^{\circ}$ for Ag-TiN, was achieved. This superhydrophilic behaviour can be associated to the open morphology of this sample (Fig. 3 section II e), with their higher roughness and imperfections that could promoted drop spread. Another point to highlight is the Ag nanoparticles embedded on TiN columns, particularly on superhydrophilic films, even having a low Ag content, the clusters were enough to promote spaces in the morphology (as it was observed in Fig. 3), being able to alter the surface wettability behaviour.

It is well known that $\mathrm{Ag}$ integration on films is always focused on antibacterial improvements [35,51-53], however in some cases, Ag has been studied as a wettability agent. For instance, Skovager et al. [54] obtained $\mathrm{TiN}$ and $\mathrm{Ag} / \mathrm{TiN}$ through unbalanced magnetron sputtering over stainless steel, and besides antibacterial test, the authors studied roughness and wettability properties. In the TiN film, the Ra was equals to $13.2 \mathrm{~nm}$ and WCA was equal to $28.3^{\circ}$, but with the silver incorporation (8.6 at.\%), the roughness and WCA changed to $15.1 \mathrm{~nm}$ and $16.6^{\circ}$ respectively. Other study case was performed by Thukkaram et al. [55] which fabricated Ag-doped $\mathrm{TiO}_{2}$ in order to obtain antibacterial properties. They revealed that with the silver incorporation into the films, Ra and WCA has shown opponent behaviour. Ag doped films displayed a hydrophilic behaviour with increasing Ra. These results show that the Ag implementation to increase the roughness and its contribution to the WCA decreasing, is consistent with the reported by Calderon et al. [25] in order to explain the change in the morphology due to the silver addition; when the silver amount is large enough, the roughness is affected significantly, changing the surface profile but if the silver content is not enough in the coating, the effect over the roughness could be the opposite. In the study case, Ag contributed to reduce WCA values significantly promoting Ra increasing, as well as a significant change on the morphology where voids appeared along to the film and facilitating the drop spreading. Otherwise, when the morphology was more compact, Ra was lower and WCA was higher. According to previous studies, superhydrophilic surfaces as Ag-TiN film obtained, probably could achieve a self-cleaning behaviour with stagnant water regime as it was achieved by Yoon and collaborators [45].

\subsection{Colour}

Although by eye, it was clearly possible to see the colour variation on samples (Fig. 6a), the colour was measured by spectrophotometry in the 1976 CIEL*a*b* space (Fig. 6b and c). All cases show intrinsic colours without interference phenomenon. Associating basic stoneware colour results $\left(L^{*}=79.65 ; a^{*}=1.76 ; b^{*}=11.95\right)$ with all deposited films, it can be sighted a decrease trending on brightness ( $\mathrm{L}^{*}$ values). In TiN system, films varied colour as $\mathrm{O}$ content was raising. The colour changed from golden (characteristic in TiN) to dark purple tone (TiONDC80). When Ag was added, the colour was different and started with dark golden in Ag:TiN sample and turned dark blue tone when had higher $\mathrm{O}$ content. In both systems (with or without $\mathrm{Ag}$ ), $\mathrm{O}_{2}$ flow promoted changes to darker colour close to blue $\left(b^{*}\right.$ in negative values and $a^{*}$ near zero), this behavior is coherent compared with results described in other studies [30,51]. It is possible to confirm that with direct current reactive magnetron sputtering technique, the film colour change can be achieved with relative easiness just changing $\mathrm{O}_{2}$ flow while the deposition is performed, making this technology suitable to obtain surfaces with desirable aesthetic properties. 


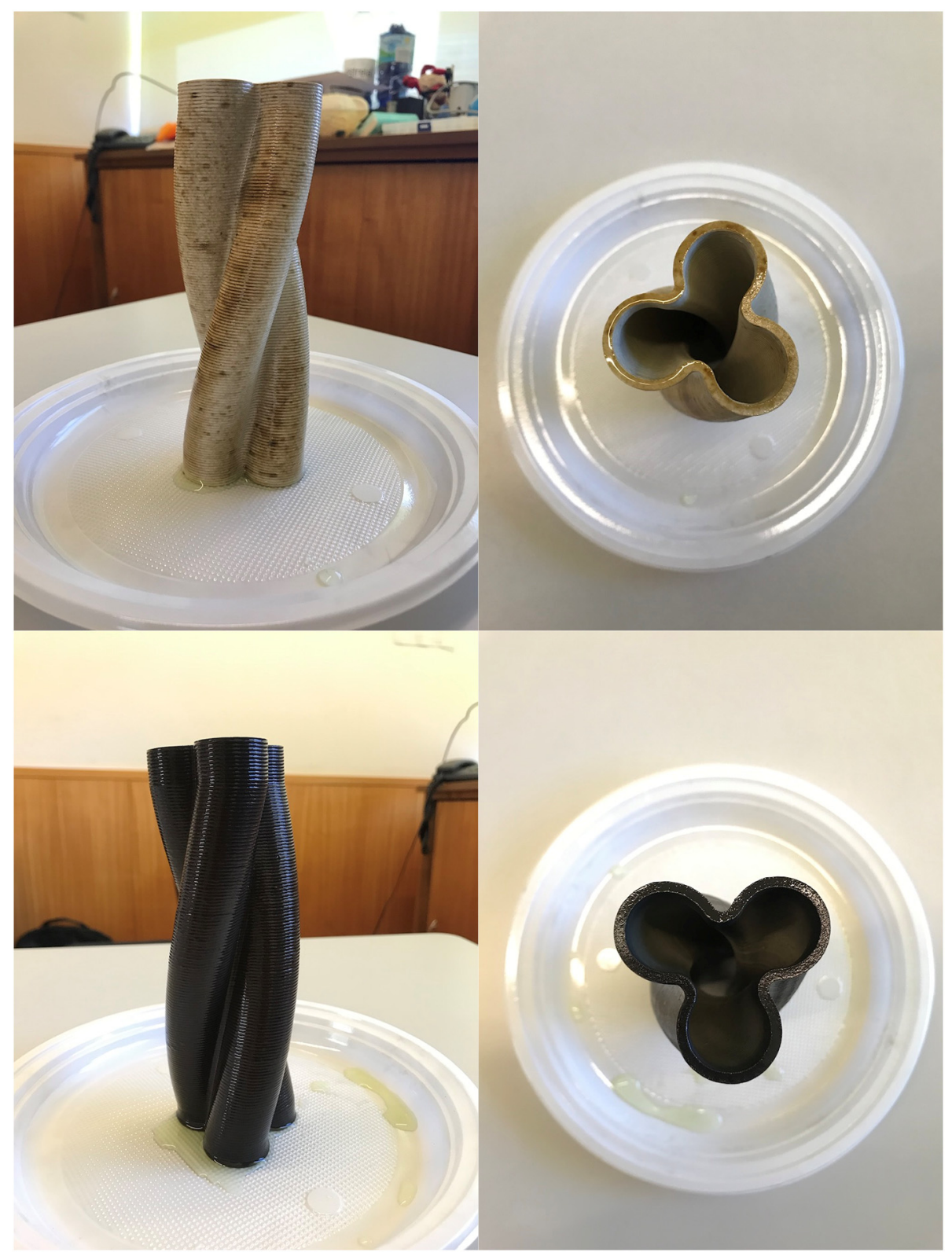

Fig. 9. Functional prototypes in 3D stoneware immersed by 60 days in aquarium water, a) uncoated and b) Ag-TiN coated.

\subsection{Antibacterial and antibiofouling tests}

Nevertheless, in order to demonstrate that obtained surfaces resist to biofouling, the following tests were performed.

The choice of samples to be tested was based on two aspects: i) the coating colour and ii) the Ag content. To this end, samples with golden (TiN) and dark purple (TiON-DC80) colours and dark golden with Ag content of 3 at.\% (Ag-TiN) and dark blue with 1 at.\% (Ag-TiON DC80) were evaluated.

Fig. 7 shows the halo test performed on the different coatings. The Halo test results demonstrate a strong influence of $\mathrm{Ag}$ nanoparticles avoiding bacterial growth in the sample's surfaces after $24 \mathrm{~h}$ of exposure - the halo, i.e. zone of inhibition, is due to silver ion release from the surface. It is possible to observe a clear halo surrounding the samples with silver, with dimensions of $1.9 \pm 0.3 \mathrm{~mm}$ and $4.1 \pm 0.4 \mathrm{~mm}$ for Ag-TiON-DC80 and Ag-TiN respectively, enhancing the antibacterial activity for the highest silver content. Meanwhile, control sample and coatings without Ag (control samples) were colonized by bacteria. These results are ascribed to silver diffusion through the agar [56] and are in agreement with the chemical composition of the samples presented on Table 2. The halo around the sample is larger on the sample containing a higher amount of silver (Fig. $7 \mathrm{~d}$ ). The results of antibacterial activity are in accordance with SEM images presented before in Fig. 3, where Ag nanoparticles are present in the film or on the samples surface, contributing for the inhibition of bacteria growth.

Fig. 8 shows the biofouling formation on samples surfaces after 2 months of immersion in water removed from an aquarium. A reduction of diatoms (microalgae) (microorganisms found in larger quantities) was observed in the coatings with $\mathrm{Ag}$ (Fig. $8 \mathrm{~d}$ and e), as also verified in the antibacterial tests (Fig. 7). The sample with the highest amount of silver, Ag-TiN showed the greatest reduction. These results agree with the antibacterial activity observed in these coatings, and with the results of Tendero et al. [57] which also obtained a decrease in biofouling formation on a nanocomposite thin film of $\mathrm{Ag}$ nanoparticles embedded in amorphous $\mathrm{Al}_{2} \mathrm{O}_{3}$ immersed for one week in riverine waters. 


\section{Conclusion}

TiN and Ag:TiN films with oxygen variation through duty cycle were performed with reactive DC magnetron sputtering technique obtaining a large range of thicknesses $(0.73-2.30 \mu \mathrm{m})$. SEM micrographs revealed that oxygen increasing in TiN coatings influenced the morphology shift to a more compact structure up to display a thick film and with Ag incorporation, nanoparticles appeared on the surface or embedded in the coating. In the cross-section views, it was possible to observe a typical columnar growth profile in all coatings. XRD showed the typical peaks for TiN system (FCC) and a strong loss of crystallinity with higher oxygen amounts. Also, the shift to higher $2 \theta$ positions in $\mathrm{Ag}$-Ti(O)N system was sighted. This behavior corresponded to the oxygen content, established by EDS results and, particularly in Ag-TiN films, it was influenced by the residual oxygen inside the coating, as can exhibited in the diffractograms. The silver incorporation into the films was evidenced with $\mathrm{Ag}$ and $\mathrm{Ag}_{2} \mathrm{O}$ diffraction peaks, despite that the samples had a low silver content, there was enough to impact the crystallinity of coating. Roughness and Wettability results demonstrated, in Ag doped films, a significant WCA decrease until achieving superhydrophilic surfaces. The colours achieved in this study for TiN system corresponded to golden tone, passing through purple tones with oxygen increasing. In $\mathrm{Ag}-\mathrm{Ti}(\mathrm{O}) \mathrm{N}$ system, the starting film displayed a dark brown tone (Ag-TiN). Dark blue was the final colour with the highest oxygen content no matter the system. Antibacterial and antibiofouling tests proved that $\mathrm{Ag}$ doped systems inhibited $S$. epidermidis and microalgae growth. Comparing to naked eye the colours before and after of antibiofouling test, all samples keep the same tones without significant changes.

So, the present study suggests that Ag-TiN system have multifunctional properties capable to resist in outdoors or aqueous environments. Based on aforementioned results, a functional prototype was coated with Ag-TiN and it was exposed during 60 days to stagnant aquarium water along with an uncoated prototype, just like the biofouling test. The prototypes were manufactured in 3D printed stoneware as the samples used in this study. After the immersion, was clear that Ag-TiN coating provides a better protection against surface formation as it can be seen in Fig. 9. This last test can demonstrate that the coatings developed by the present study can be easily tuneable to the desirable decorative purposes with antibacterial and antibiofouling potential effects, making these films an option to be applied in architectural stoneware parts made by AM.

\section{CRediT authorship contribution statement}

José D. Castro: Investigation, Formal analysis, Data curation, Writing - original draft, Visualization. E. Carneiro: Investigation, Writing - review \& editing. S.M. Marques: Writing - review \& editing, Visualization. Bruno Figueiredo: Conceptualization, Methodology. Antonio J. Pontes: Conceptualization, Methodology. Álvaro M. Sampaio: Conceptualization, Methodology. Isabel Carvalho: Investigation, Writing - original draft, Visualization. Mariana Henriques: Conceptualization, Methodology, Supervision, Writing review \& editing. Paulo J.S. Cruz: Project administration, Funding acquisition. S. Carvalho: Conceptualization, Methodology, Supervision, Writing - review \& editing, Project administration, Funding acquisition.

\section{Declaration of competing interest}

The authors declare that they have no known competing financial interests or personal relationships that could have appeared to influence the work reported in this paper.

\section{Acknowledgements}

The authors acknowledge to MIT Portugal-2017 program by the financial support through FCT/MCTES for this exploratory research project with the reference MIT-EXPL/ISF/0006/2007 and Physics Center of University of Minho and University of Porto (CFUM-UP) by its support though the strategical project (UID/FIS/04650/2019). This study was supported by the Portuguese Foundation for Science and Technology (FCT) under the scope of the strategic funding of UID/FIS/ 04650/2019 and UID/BIO/04469/2019 unit and BioTecNorte operation (NORTE-01-0145-FEDER-000004) funded by the European Regional Development Fund under the scope of Norte2020 — Programa Operacional Regional do Norte and, in the framework of the ATRITO-0 (co-financed via FEDER (PT2020) POCI-01-0145-FEDER-030446 and FCT (PIDDAC)) and the On-SURF (co-financed via FEDER (PT2020) POCI-01-0247-FEDER-024521) projects.

\section{References}

[1] G. Serin, H.O. Unver, N. Durlu, A review of additive manufacturing technologies, 17th Int. Conf. Mach. Des. Prod., Bursa, Turkey, 2016.

[2] S. Singh, S. Ramakrishna, R. Singh, Material issues in additive manufacturing: a review, J. Manuf. Process. 25 (2017) 185-200, https://doi.org/10.1016/j.jmapro. 2016.11.006.

[3] M. Yakout, M.A. Elbestawi, S.C. Veldhuis, A review of metal additive manufacturing technologies, Solid State Phenom. 278 (2018) 1-14, https://doi.org/10.4028/ www.scientific.net/SSP.278.1.

[4] M.L. Coutinho, A.Z. Miller, M.F. Macedo, Biological colonization and biodeterioration of architectural ceramic materials: an overview, J. Cult. Herit. 16 (2015) 759-777, https://doi.org/10.1016/j.culher.2015.01.006.

[5] W. Callister, D. Rethwisch, Materials science and engineering: an introduction, Eighth edi, John Wiley \&amp; Sons, Inc., 2007, http://sinnott.mse.ufl.edu/ Syllabus_abet_3010_2007_v02.pdf , Accessed date: 6 January 2015.

[6] Z. Wei, L. Cheng, Y. Ma, A. Chen, X. Guo, J. Wu, Y. Shi, Direct fabrication mechanism of pre-sintered $\mathrm{Si}_{3} \mathrm{~N}_{4}$ ceramic with ultra-high porosity by laser additive manufacturing, Scr. Mater. 173 (2019) 91-95, https://doi.org/10.1016/j. scriptamat.2019.07.046.

[7] A. Dasan, H. Elsayed, J. Kraxner, D. Galusek, E. Bernardo, Hierarchically porous 3D printed akermanite scaffolds from silicones and engineered fillers, J. Eur. Ceram. Soc. 39 (2019) 4445-4449, https://doi.org/10.1016/j.jeurceramsoc.2019.06.021.

[8] C. Gaylarde, M. Ribas Silva, T. Warscheid, 'Microbial impacts on building materials - weathering and conservation'. Microbial impact on building materials: an overview, Mater. Struct. / Matdriaux Constr. Chairlady M. Ribas Silva. 36 (2003) 342-352.

[9] J.J. Ortega-Calvo, M. Hernandez-Marine, C. Saiz-Jimenez, Biodeterioration of building materials by cyanobacteria and algae, Int. Biodeterior. 28 (1991) 165-185, https://doi.org/10.1016/0265-3036(91)90041-O.

[10] F. Bastian, V. Jurado, A. Nováková, C. Alabouvette, C. Saiz-Jimenez, The microbiology of Lascaux Cave, Microbiology 156 (2010) 644-652, https://doi.org/10. 1099/mic.0.036160-0.

[11] B. Spangl, G. Ellersdorfer, K. Lopandic, J.D. Ettenauer, K. Sterflinger, G. Piñar, C. Voitl, Microbes on building materials - evaluation of DNA extraction protocols as common basis for molecular analysis, Sci. Total Environ. 439 (2012) 44-53, https://doi.org/10.1016/j.scitotenv.2012.09.005.

[12] N.S. Allen, M. Edge, J. Verran, J. Stratton, J. Maltby, C. Bygott, Photocatalytic titania based surfaces: environmental benefits, Polym. Degrad. Stab. 93 (2008) 1632-1646, https://doi.org/10.1016/j.polymdegradstab. 2008.04.015.

[13] L. Caballero, K.A. Whitehead, N.S. Allen, J. Verran, Photoinactivation of Escherichia coli on acrylic paint formulations using fluorescent light, Dyes Pigments 86 (2010) 56-62, https://doi.org/10.1016/j.dyepig.2009.12.001.

[14] K.L. Uemoto, N.M.N. Sato, V. John, Influence of the mix proportion of mortars and paint formulation on the behaviour of the mortar/coating system in water transport phenomena, 11DBMC Int. Conférence Durab. Build. Mater. Components, Istanbul, Turkey, 2008, p. 8.

[15] A. Synnefa, M. Santamouris, K. Apostolakis, On the development, optical properties and thermal performance of cool colored coatings for the urban environment, Sol. Energy 81 (2007) 488-497, https://doi.org/10.1016/j.solener.2006.08.005.

[16] M. Santamouris, K. Pavlou, D. Kolokotsa, A. Synnefa, K. Niachou, Recent progress on passive cooling techniques, Energy Build 39 (2007) 859-866, https://doi.org/ 10.1016/j.enbuild.2007.02.008.

[17] M. Pagliaro, R. Ciriminna, G. Palmisano, Silica-based hybrid coatings, J. Mater. Chem. 19 (2009) 3116-3126, https://doi.org/10.1039/b819615j.

[18] A. Kumar, P.K. Vemula, P.M. Ajayan, G. John, Silver-nanoparticle-embedded antimicrobial paints based on vegetable oil, Nat. Mater. 7 (2008) 236-241, https://doi. org/10.1038/nmat2099.

[19] J. Zhang, S. Zhou, Y. Wang, Y. Wang, C. Wang, X. Lu, C. Mao, S. Chen, X. Lu, L. Wang, Enhancing anti-corrosion and antifouling properties of $\mathrm{Cu} / \mathrm{GLC}$ composite film for marine application, Surf. Coatings Technol. 375 (2019) 414-426, https:// doi.org/10.1016/j.surfcoat.2019.07.054.

[20] K. Sun, H. Yang, W. Xue, A. He, D. Zhu, W. Liu, K. Adeyemi, Y. Cao, Anti-biofouling 
superhydrophobic surface fabricated by picosecond laser texturing of stainless steel, Appl. Surf. Sci. 436 (2018) 263-267, https://doi.org/10.1016/j.apsusc.2017.12. 012.

[21] V.D. Bui, J.W. Mwangi, A. Schubert, Powder mixed electrical discharge machining for antibacterial coating on titanium implant surfaces, J. Manuf. Process. 44 (2019) 261-270, https://doi.org/10.1016/j.jmapro.2019.05.032.

[22] I. Carvalho, M. Henriques, J.C. Oliveira, C.F.A. Alves, A.P. Piedade, S. Carvalho, Influence of surface features on the adhesion of staphylococcus epidermidis to AgTiCN thin films, Sci. Technol. Adv. Mater. 14 (2013), https://doi.org/10.1088/ 1468-6996/14/3/035009.

[23] M. Qiu, C. He, Novel zwitterion-silver nanocomposite modified thin-film composite forward osmosis membrane with simultaneous improved water flux and biofouling resistance property, Appl. Surf. Sci. 455 (2018) 492-501, https://doi.org/10.1016/ j.apsusc.2018.06.020.

[24] N.K. Manninen, F. Ribeiro, A. Escudeiro, T. Polcar, S. Carvalho, A. Cavaleiro, Influence of Ag content on mechanical and tribological behavior of DLC coatings, Surf. Coatings Technol. 232 (2013) 440-446, https://doi.org/10.1016/j.surfcoat. 2013.05.048.

[25] S. Calderon Velasco, A. Cavaleiro, S. Carvalho, Functional properties of ceramic-Ag nanocomposite coatings produced by magnetron sputtering, Prog. Mater. Sci. 84 (2016) 158-191, https://doi.org/10.1016/j.pmatsci.2016.09.005.

[26] J.M. Chappé, N. Martin, J. Lintymer, F. Sthal, G. Terwagne, J. Takadoum, Titanium oxynitride thin films sputter deposited by the reactive gas pulsing process, Appl. Surf. Sci. 253 (2007) 5312-5316, https://doi.org/10.1016/j.apsusc.2006.12.004.

[27] N. Martin, J. Lintymer, J. Gavoille, J.M. Chappé, F. Sthal, J. Takadoum, F. Vaz, L. Rebouta, Reactive sputtering of $\mathrm{TiO}_{\mathrm{x}} \mathrm{N}_{\mathrm{y}}$ coatings by the reactive gas pulsing process. Part I: pattern and period of pulses, Surf. Coatings Technol. 201 (2007) 7720-7726, https://doi.org/10.1016/j.surfcoat.2007.03.002.

[28] N. Martin, J. Lintymer, J. Gavoille, J.M. Chappé, F. Sthal, J. Takadoum, F. Vaz, L. Rebouta, Reactive sputtering of $\mathrm{TiO}_{\mathrm{x}} \mathrm{N}_{\mathrm{y}}$ coatings by the reactive gas pulsing process: part III: the particular case of exponential pulses, Surf. Coatings Technol. 201 (2007) 7733-7738, https://doi.org/10.1016/j.surfcoat.2007.03.022.

[29] N. Martin, J. Lintymer, J. Gavoille, J.M. Chappé, F. Sthal, J. Takadoum, F. Vaz, L. Rebouta, Reactive sputtering of $\mathrm{TiO}_{\mathrm{x}} \mathrm{N}_{\mathrm{y}}$ coatings by the reactive gas pulsing process. Part II: the role of the duty cycle, Surf. Coatings Technol. 201 (2007) 7727-7732, https://doi.org/10.1016/j.surfcoat.2007.03.021.

[30] F. Vaz, P. Cerqueira, L. Rebouta, S.M.C. Nascimento, E. Alves, P. Goudeau, J.P. Rivière, K. Pischow, J. De Rijk, Structural, optical and mechanical properties of coloured $\mathrm{TiN}_{\mathrm{x}} \mathrm{O}_{\mathrm{y}}$ thin films, Thin Solid Films 447-448 (2004) 449-454, https://doi. org/10.1016/S0040-6090(03)01123-4.

[31] P. Carvalho, L. Cunha, E. Alves, N. Martin, E. Le Bourhis, F. Vaz, $\mathrm{ZrO}_{\mathrm{x}} \mathrm{N}_{\mathrm{y}}$ decorative thin films prepared by the reactive gas pulsing process, J. Phys. D. Appl. Phys. 42 (2009), https://doi.org/10.1088/0022-3727/42/19/195501.

[32] A. Bauer, W. Kirby, J. Sherris, M. Turk, Antibiotic susceptibility testing by standard single disk method, Am. J. Clin. Pathol. 45 (1966) 493-496.

[33] M. Ohring, Materials Science of Thin Films, Second edition, (2002), https://doi. org/10.1016/B978-0-12-524975-1.50018-5.

[34] N.K. Manninen, R.E. Galindo, S. Carvalho, A. Cavaleiro, Silver surface segregation in Ag-DLC nanocomposite coatings, Surf. Coatings Technol. 267 (2015) 90-97, https://doi.org/10.1016/j.surfcoat.2014.12.029.

[35] I. Ferreri, S. Calderon V, R. Escobar Galindo, C. Palacio, M. Henriques, A.P. Piedade, S. Carvalho, Silver activation on thin films of Ag-ZrCN coatings for antimicrobial activity, Mater. Sci. Eng. C 55 (2015) 547-555, https://doi.org/10.1016/j.msec. 2015.05.071.

[36] S.M. Marques, I. Carvalho, M. Henriques, T. Polcar, S. Carvalho, PVD-grown antibacterial Ag-TiN films on piezoelectric PVDF substrates for sensor applications, Surf. Coatings Technol. 281 (2015) 117-124, https://doi.org/10.1016/j.surfcoat. 2015.09.057.

[37] C. Lopes, C. Gonçalves, P. Pedrosa, F. Macedo, E. Alves, N.P. Barradas, N. Martin, C. Fonseca, F. Vaz, $\mathrm{TiAg}_{\mathrm{x}}$ thin films for lower limb prosthesis pressure sensors: effect of composition and structural changes on the electrical and thermal response of the films, Appl. Surf. Sci. 285 (2013) 10-18, https://doi.org/10.1016/j.apsusc.2013. 07.021.

[38] J.A. Thornton, Structure-zone models of thin films, in: M.R. Jacobson (Ed.), SPIE Proc. Vol. 0821 Model. Opt. Thin Film, 1988, p. 95, , https://doi.org/10.1117/12. 941846.

[39] J.M. Chappé, N. Martin, J.F. Pierson, G. Terwagne, J. Lintymer, J. Gavoille, J. Takadoum, Influence of substrate temperature on titanium oxynitride thin films prepared by reactive sputtering, Appl. Surf. Sci. 225 (2004) 29-38, https://doi.org/ 10.1016/j.apsusc.2003.09.028.
[40] P. Gu, X. Zhu, J. Li, H. Wu, D. Yang, Influence of substrate and $\mathrm{Ar} / \mathrm{N}_{2}$ gas flow ratio on structural, optical and electrical properties of TiN thin films synthetized by DC magnetron sputtering, J. Mater. Sci. Mater. Electron. 29 (2018) 9893-9900, https://doi.org/10.1007/s10854-018-9031-2.

[41] H. Liang, J. Xu, D. Zhou, X. Sun, S. Chu, Y. Bai, Thickness dependent microstructural and electrical properties of TiN thin films prepared by DC reactive magnetron sputtering, Ceram. Int. 42 (2016) 2642-2647, https://doi.org/10.1016/ j.ceramint.2015.10.070.

[42] P. Pedrosa, E. Alves, N. Martin, J. Haueisen, N.P. Barradas, F. Vaz, B. Vasconcelos, P. Fiedler, D. Machado, C. Fonseca, Electrochemical characterization of nanostructured Ag:TiN thin films produced by glancing angle deposition on polyurethane substrates for bio-electrode applications, J. Electroanal. Chem. 768 (2016) 110-120, https://doi.org/10.1016/j.jelechem.2016.03.005.

[43] B. Subramanian, R. Ananthakumar, V.S. Vidhya, M. Jayachandran, Influence of substrate temperature on the materials properties of reactive DC magnetron sputtered Ti/TiN multilayered thin films, Mater. Sci. Eng. B Solid-State Mater. Adv. Technol. 176 (2011) 1-7, https://doi.org/10.1016/j.mseb.2010.08.004.

[44] K.L. Chuang, M.T. Tsai, F.H. Lu, Morphology control of conductive TiN films produced by air-based magnetron sputtering, Surf. Coatings Technol. 350 (2018) 1091-1097, https://doi.org/10.1016/j.surfcoat.2018.02.020.

[45] S.H. Yoon, N. Rungraeng, W. Song, S. Jun, Superhydrophobic and superhydrophilic nanocomposite coatings for preventing Escherichia coli K-12 adhesion on food contact surface, J. Food Eng. 131 (2014) 135-141, https://doi.org/10.1016/j. jfoodeng.2014.01.031.

[46] S.P. Rodrigues, C.F.A. Alves, A. Cavaleiro, S. Carvalho, Water and oil wettability of anodized 6016 aluminum alloy surface, Appl. Surf. Sci. 422 (2017) 430-442, https://doi.org/10.1016/j.apsusc.2017.05.204.

[47] J. Drelich, E. Chibowski, D.D. Meng, K. Terpilowski, Hydrophilic and superhydrophilic surfaces and materials, Soft Matter 7 (2011) 9804, https://doi.org/10. 1039/c1sm05849e.

[48] E.P. Ivanova, R.J. Crawford, Antibacterial Surfaces, Springer International Publishing, Cham, 2015, https://doi.org/10.1007/978-3-319-18594-1.

[49] T.A. Otitoju, A.L. Ahmad, B.S. Ooi, Superhydrophilic (superwetting) surfaces: a review on fabrication and application, J. Ind. Eng. Chem. 47 (2017) 19-40, https:// doi.org/10.1016/j.jiec.2016.12.016.

[50] B. Bharti, S. Kumar, R. Kumar, Superhydrophilic $\mathrm{TiO}_{2}$ thin film by nanometer scale surface roughness and dangling bonds, Appl. Surf. Sci. 364 (2016) 51-60, https:// doi.org/10.1016/j.apsusc.2015.12.108.

[51] S. Rtimi, O. Baghriche, R. Sanjines, C. Pulgarin, M. Bensimon, J. Kiwi, TiON and TiON-Ag sputtered surfaces leading to bacterial inactivation under indoor actinic light, J. Photochem. Photobiol. A Chem. 256 (2013) 52-63, https://doi.org/10. 1016/j.jphotochem.2013.02.005.

[52] P.J. Kelly, H. Li, P.S. Benson, K.A. Whitehead, J. Verran, R.D. Arnell, I. Iordanova, Comparison of the tribological and antimicrobial properties of $\mathrm{CrN} / \mathrm{Ag}, \mathrm{ZrN} / \mathrm{Ag}$, TiN/Ag, and TiN/Cu nanocomposite coatings, Surf. Coatings Technol. 205 (2010) 1606-1610, https://doi.org/10.1016/j.surfcoat.2010.07.029.

[53] P. Navabpour, S. Ostovarpour, J. Hampshire, P. Kelly, J. Verran, K. Cooke, The effect of process parameters on the structure, photocatalytic and self-cleaning properties of $\mathrm{TiO}_{2}$ and $\mathrm{Ag}-\mathrm{TiO}_{2}$ coatings deposited using reactive magnetron sputtering, Thin Solid Films 571 (2014) 75-83, https://doi.org/10.1016/j.tsf.2014.10. 040.

[54] A. Skovager, K. Whitehead, D. Wickens, J. Verran, H. Ingmer, N. Arneborg, A comparative study of fine polished stainless steel, TiN and TiN/Ag surfaces: adhesion and attachment strength of Listeria monocytogenes as well as anti-listerial effect, Colloids Surfaces B Biointerfaces 109 (2013) 190-196, https://doi.org/10. 1016/j.colsurfb.2013.03.044.

[55] M. Thukkaram, P. Cools, A. Nikiforov, P. Rigole, P. Van Der Voort, G. Du Laing, C. Vercruysse, R. Morent, L. De Wilde, P. De Baets, K. Verbeken, N. De Geyter, Antibacterial activity of a porous silver doped $\mathrm{TiO}_{2}$ coating on titanium substrates synthesized by plasma electrolytic oxidation, Appl. Surf. Sci. (2019) 144235, , https://doi.org/10.1016/j.apsusc.2019.144235.

[56] S.M.M. Marques, I. Carvalho, M. Henriques, T. Polcar, S. Carvalho, PVD-grown antibacterial Ag-TiN films on piezoelectric PVDF substrates for sensor applications, Surf. Coatings Technol. 281 (2015) 117-124, https://doi.org/10.1016/j.surfcoat. 2015.09.057.

[57] C. Tendero, A.M. Lazar, D. Samélor, O. Debieu, V. Constantoudis, G. Papavieros, A. Villeneuve, C. Vahlas, Nanocomposite thin film of Ag nanoparticles embedded in amorphous $\mathrm{Al}_{2} \mathrm{O}_{3}$ on optical sensors windows: synthesis, characterization and targeted application towards transparency and anti-biofouling, Surf. Coatings Technol. 328 (2017) 371-377, https://doi.org/10.1016/j.surfcoat.2017.08.061. 